Revista Española de Antropología Americana ISSN: 0556-6533

https://doi.org/10.5209/reaa.64961

\title{
El mural de Chilonché: estudio preliminar
}

\author{
Gaspar Muñoz Cosme ${ }^{1}$ y Cristina Vidal Lorenzo ${ }^{2}$
}

Recibido: 15 de febrero de 2019 / Aceptado: 24 de febrero de 2019

Resumen. El artículo presenta la investigación llevada a cabo en uno de los cuartos del Palacio 3E1 de la Acrópolis de Chilonché (Petén, Guatemala), en cuyo interior se descubrió un mural pintado por los mayas en el Clásico Tardío con escenas figurativas de indudable valor artístico. Esta contribución se centra en cinco aspectos principales: su descubrimiento, excavación, conservación, documentación y análisis iconográfico del mural.

Palabras clave: pintura mural; Chilonché; Clásico Tardío; patrimonio en riesgo; maya.

\section{[en] The Mural of Chilonché: A Preliminary Study}

\begin{abstract}
This paper presents the research carried out in one of the rooms of the Palace 3E1 of the Acropolis of Chilonché (Petén, Guatemala). Inside, a mural painted by the Maya in the Late Classic with figurative scenes of unquestionable artistic value, was discovered. Five main aspects are the focus of this contribution: its discovery, excavation, conservation, documentation and iconographic analysis of the mural.
\end{abstract}

Keywords: mural painting; Chilonché; Late Classic; heritage at risk; Maya.

Sumario. 1. El descubrimiento. 2. Excavación del cuarto de las pinturas. 3. Conservación y documentación. 4. Análisis formal. 5. Aproximación al significado. 6. Un patrimonio en riesgo. 7. Referencias.

Cómo citar: Muñoz Cosme, Gaspar y Cristina Vidal Lorenzo. 2019. «El mural de Chilonché, estudio preliminar». Revista Española de Antropología Americana 49 (número especial): 77-96.

\section{El descubrimiento}

Conocimos Chilonché durante una expedición científica organizada para visitar sitios arqueológicos mayas con arquitectura visible en riesgo de destrucción, en la cuenca del río Mopán (Petén, Guatemala). Era el mes de julio de 2005 y nada más llegar a la plaza situada al sur de la Acrópolis pudimos observar los enormes y profundos túneles de saqueo que la habían socavado. Dando vuelta por el oriente llegamos a la fachada norte $y$, tras atravesar una sala exterior que estaba casi destruida, accedimos a otra estancia a través de un singular arco poligonal. En su interior se podía apreciar una bóveda que había sido parcialmente rellenada, así como algunos restos de pintura mural, que ya habían sido reseñados unos años antes por los investigadores del

\footnotetext{
1 Universidad Politécnica de Valencia. gmcosme@upv.es

2 Universidad de Valencia. cristina.vidal@uv.es
} 


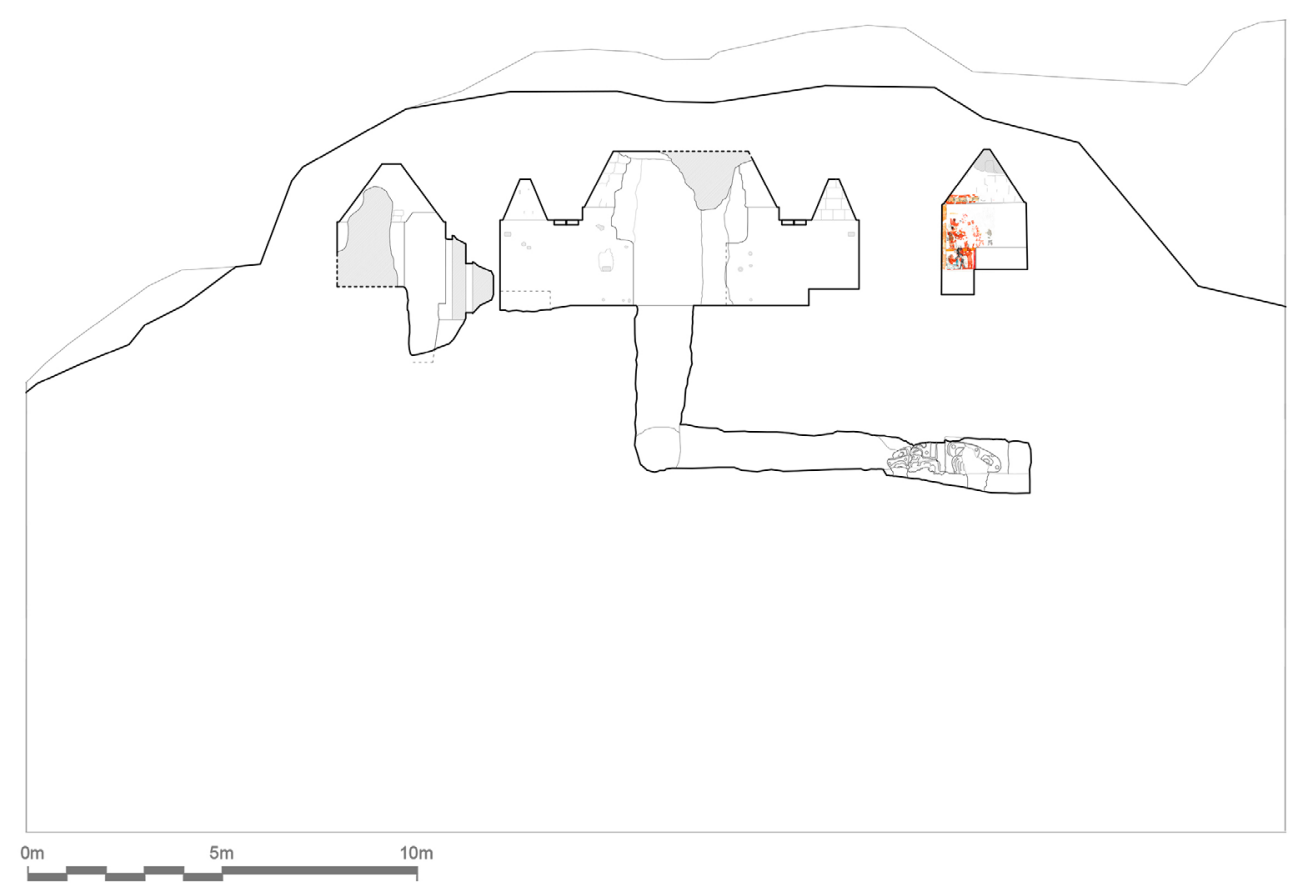

Figura 1. Sección del ala norte de la Acrópolis de Chilonché en la que se aprecia el túnel de saqueo en el que se encontró el mascarón. (C) PLB 2018).

Proyecto Atlas Arqueológico de Guatemala (Chocón et al. 1999: 289-291). Ascendiendo por dicha fachada, observamos también varios cuartos que habían perdido los muros de la fachada septentrional y que estaban abiertos y semidestruidos a causa de los derrumbes y socavones, en parte provocados por la gran cantidad de túneles de saqueo que perforaban todo este conjunto monumental.

Las arquitecturas de la parte alta de la fachada occidental presentaban un estado de deterioro similar, destacando en este sector una estancia con una escalera con sillares perfectamente labrados que conducía a un nivel superior. Y poco más pudimos vislumbrar, salvo un entorno cubierto de espesa maleza y la enorme extensión de un paisaje de potreros y cultivos que se divisaba desde lo más alto de la Acrópolis.

Años más tarde, en marzo de 2009, y como parte de un programa de reconocimiento de sitios con arquitectura en peligro, un equipo del Proyecto La Blanca ${ }^{3}$ regresó a Chilonché para documentar, mediante croquis, fotografías y mediciones, la arquitectura visible de la Acrópolis. Al penetrar en un túnel de saqueo que había sido realizado no mucho tiempo atrás en el centro de la fachada norte encontraron una enorme escultura zoomorfa revestida de estuco que aún conservaba restos de policromía. Se dedujo que formaba parte de la ornamentación de la fachada de una de las subestructuras más profundas de la Acrópolis y que debía pertenecer a una época muy temprana. Su estado aparente de conservación era bueno, aunque algunas pequeñas partes habían sido dañadas durante la excavación de saqueo. Se tomaron fotografías y se levantaron croquis

3 El Proyecto La Blanca está dirigido por Cristina Vidal Lorenzo y Gaspar Muñoz Cosme. Desde el año 2004 realiza excavaciones y puesta en valor del patrimonio cultural en el sitio arqueológico La Blanca (Petén, Guatemala). 


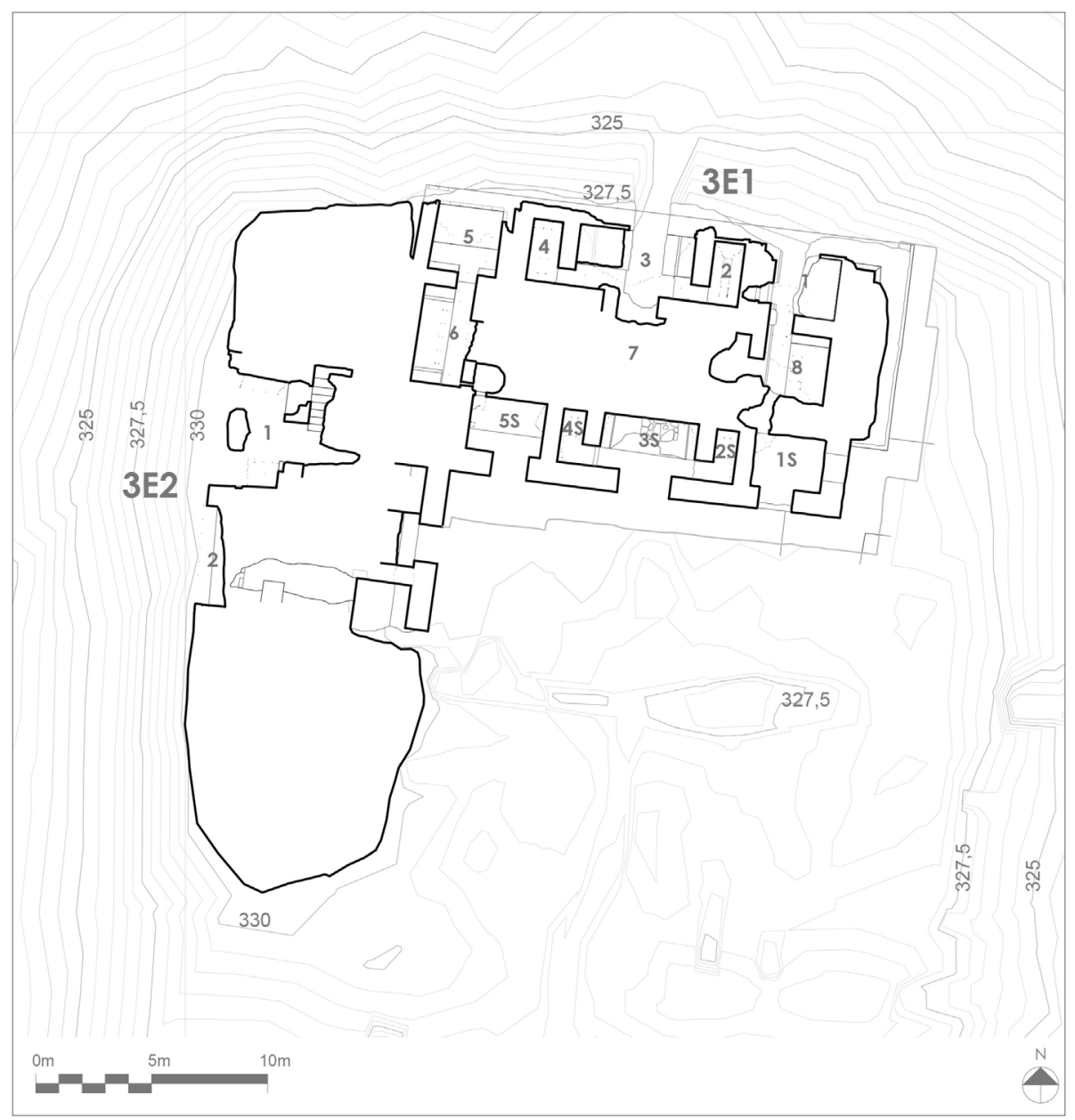

Figura 2. Planta general de la Acrópolis de Chilonché con indicación de los cuartos originales del Palacio 3E1 y del ala sur, perteneciente a una fase constructiva posterior. (C) PLB 2013).

con los datos necesarios para notificarlos a las autoridades del Instituto de Antropología e Historia de Guatemala, al tiempo que se hizo el ofrecimiento de realizar una operación de salvamento de esta singular pieza escultórica, conocida desde entonces como el mascarón de Chilonché (Muñoz et al. 2014a: 103) (Figura 1).

Este hecho fue el origen de que se programaran unas acciones en este sitio arqueológico durante las temporadas de campo 2009 y 2010 del Proyecto La Blanca, con el propósito de realizar las operaciones de salvamento, conservación y documentación del mascarón y continuar con el levantamiento y documentación de los vestigios constructivos de la parte superior. Así se obtuvieron los primeros planos del que hemos denominado Palacio 3E1, situado al norte de la Acrópolis, el cual presenta cinco estancias que han perdido total o parcialmente sus muros septentrionales (Figura 2). 
FASE 1

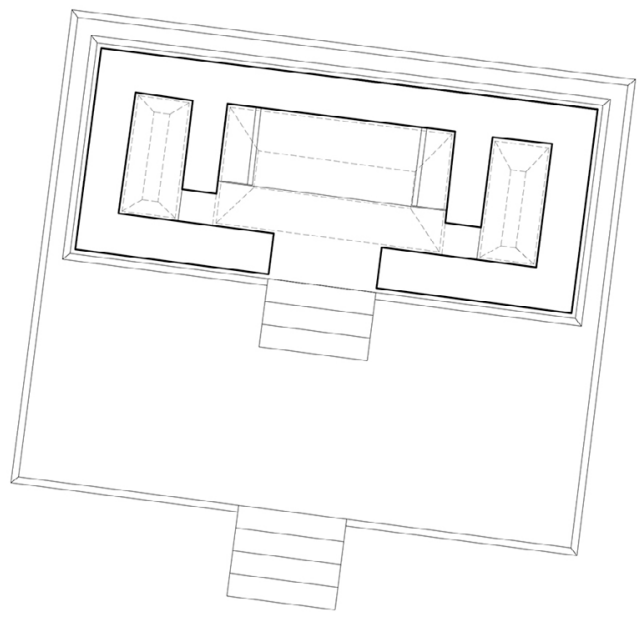

FASE 2
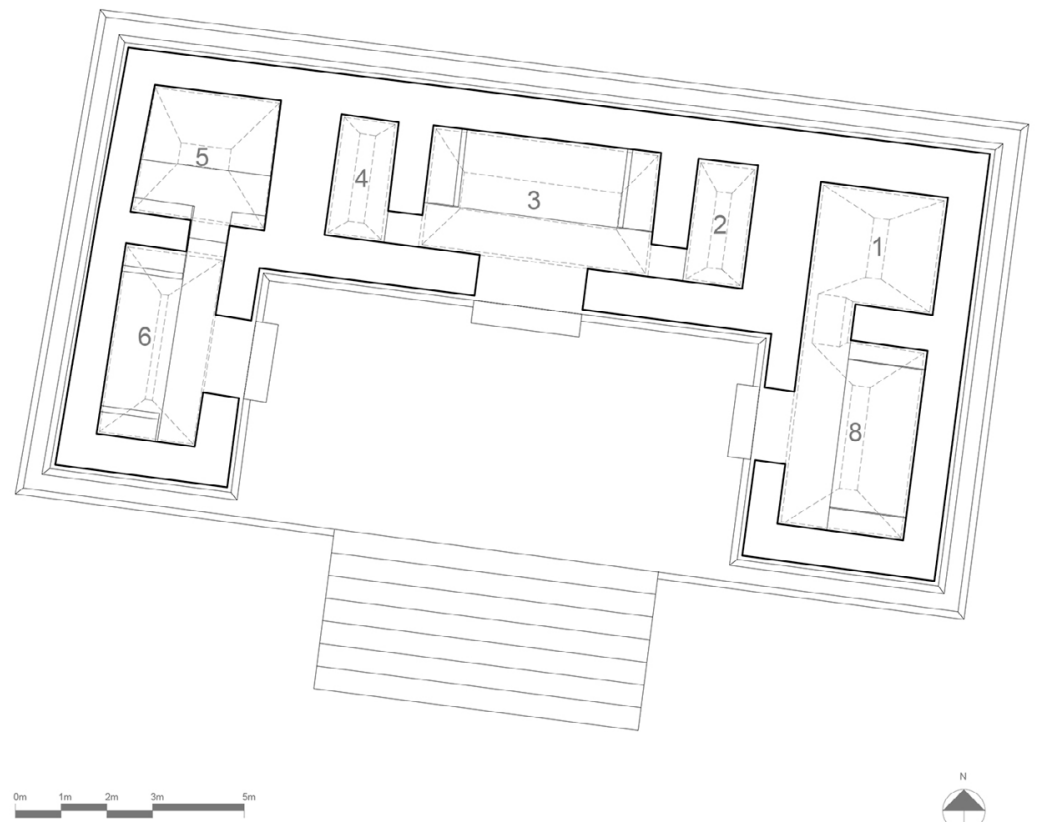

Figura 3. Evolución constructiva del Palacio 3E1. (C PLB 2018). 
Un nuevo intento de saqueo ocurrido en los primeros meses de 2011 motivó que se organizara una expedición de urgencia en el mes de marzo de dicho año. Una vez personados en el sitio fuimos testigos de la existencia de un boquete en el arranque de la bóveda de uno de los cuartos de ese palacio (cuarto 6). Para ello, los saqueadores se introdujeron en el contiguo cuarto 5 -que había perdido su fachada norte-y extrajeron cuatro dovelas de ambas caras de las bóvedas con el fin de dejar un paso abierto para acceder al interior del cuarto 6, el cual había sido totalmente rellenado por los mayas antiguos tras la clausura de estas estancias palaciegas con el fin de realizar una nueva construcción de mayor tamaño. Este relleno de piedra y tierra llegaba a pocos centímetros del arranque de la bóveda, dejando un espacio vacante de no más de $1,5 \mathrm{~m}$ en las partes más altas de la misma. Además, en el extremo sur, una acumulación de sillares formaba una suerte de apeo o cierre de las claves de la bóveda, posiblemente por haber sido éste el lugar que utilizaron los mayas para rellenar la sala.

En un primer reconocimiento se pudo vislumbrar la presencia de una cenefa, de unos $25 \mathrm{~cm}$ de anchura, que recorría la parte inferior de la bóveda, con escritura jeroglífica enmarcada en dos gruesas franjas de color rojo. También se podía ver la impronta de una mano de color negro en la mitad de la bóveda oriental y algunas pinturas figurativas de colores llamativos en la zona que aún quedaba visible de los muros. Dedujimos que la sala tenía algo más de $4 \mathrm{~m}$ de longitud por algo más de $2 \mathrm{~m}$ de anchura, aunque era difícil apreciarlo en esa situación. Una vez tomadas las primeras fotografías se notificó el hallazgo y el intento de saqueo a los responsables del Instituto de Antropología e Historia de Guatemala, y se preparó una operación para el vaciado del cuarto y para la aplicación de tratamientos de consolidación, limpieza y conservación de la arquitectura y de los vestigios pictóricos.

\section{Excavación del cuarto de las pinturas}

El cuarto 6 del Palacio 3E1, o cuarto de las pinturas de Chilonché como se le denominó a partir de entonces, se vació partiendo previamente del desescombro del cuarto 5 . Así se descubrió una puerta de unos $0,80 \mathrm{~m}$ de anchura justo debajo de la perforación que habían hecho los saqueadores en la bóveda, de forma que se pudieron iniciar las labores de vaciado de una forma ordenada y metódica a través de este vano, una vez desmontado el tapón de sillares y piedras con el que había sido clausurado. Dado que a esta puerta se le habían extraído las vigas que conformaban su dintel, presumiblemente para ser utilizadas en la nueva construcción, se decidió colocar un nuevo dintel, algo necesario para poder reconstruir el boquete practicado en la bóveda y garantizar la seguridad de todas las operaciones de vaciado y limpieza del cuarto.

Al vaciar la sala pudimos comprobar que, excepto el muro oriental, los otros tres lienzos de paredes verticales estaban totalmente cubiertos por pinturas murales en las que se distinguían diferentes escenas con un gran número de personajes. Resulta difícil describir la emoción que supuso para todo el equipo del Proyecto La Blanca contemplar esta cámara repleta de pinturas, que parecían rivalizar en belleza y calidad con las de Bonampak, y que habíamos logrado salvar de una inminente destrucción. Fue entonces también cuando invitamos a Alfonso Lacadena a incorporarse a este proyecto en calidad de epigrafista.

La estancia tiene una longitud de 4,22 $\mathrm{m}$ y una anchura de $2,17 \mathrm{~m}$, más de la mitad oriental de la misma está ocupada por una banqueta de $0,65 \mathrm{~m}$ de altura y una 


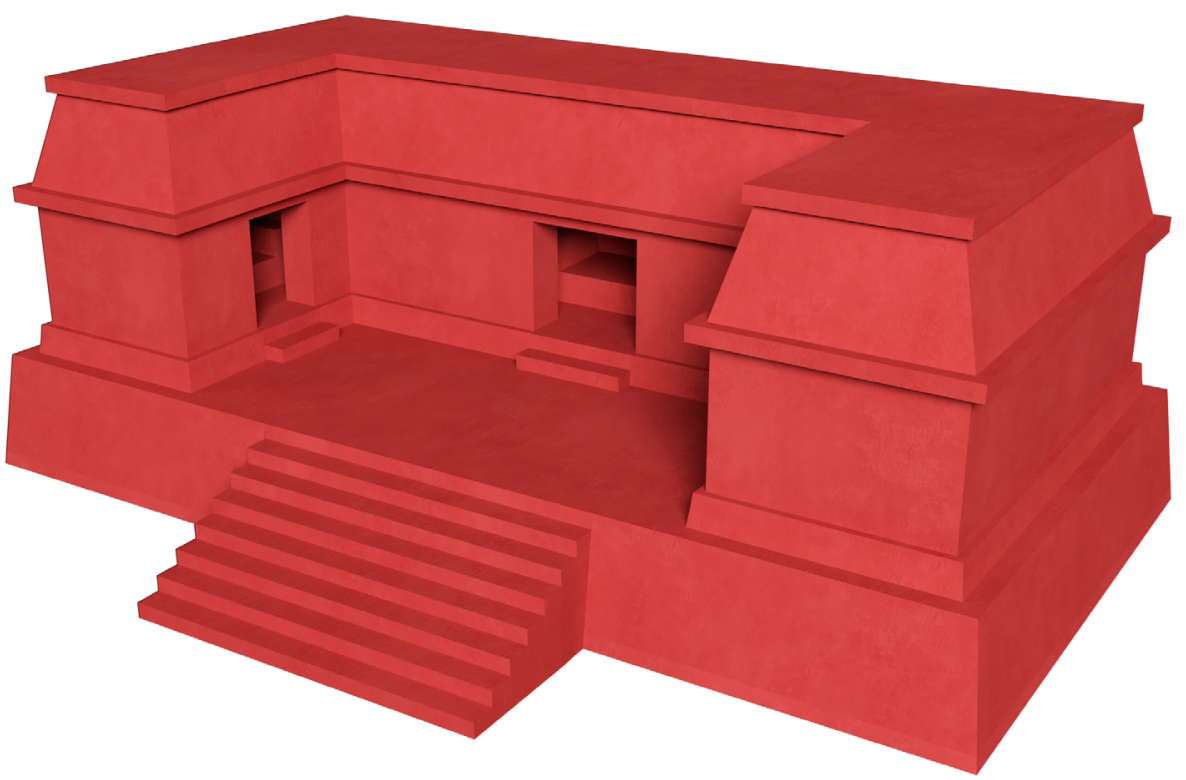

Figura 4. Reconstrucción ideal de la segunda fase constructiva del Palacio 3E1. (C PLB 2018).

anchura de 1,35 m, con dos brazos laterales ataludados y anexos a los muros norte y sur. Es de destacar que el cuarto está cubierto mediante una bóveda de cuatro lados con las pendientes de sus planos de entre $55^{\circ}$ y $58^{\circ}$ respecto a la horizontal, es decir que los cuatro lados de su bóveda están construidos con dovelas y trabajan como bóveda, lo que no es muy habitual en otros sitios de Petén en el que los hastiales de las cubiertas abovedadas son muros con un leve desplome y se construyen con sillares y no con dovelas. La altura hasta la tapa o clave desde el pavimento es de unos 3,70 $\mathrm{m}$, y los muros alcanzan los $2,35 \mathrm{~m}$ hasta el arranque de la bóveda, que se produce mediante un pequeño voladizo de unos $0,08 \mathrm{~m}$, y de ahí sube hasta la clave que tiene una anchura visible de $0,16 \mathrm{~m}$. Con todas estas características nos hallábamos ante una estancia de unos $9 \mathrm{~m}^{2}$ de superficie y con un área total de pintura mural de aproximadamente $12 \mathrm{~m}^{2}$.

Una vez realizado el análisis y estudio del edificio 3E1, pudimos deducir la evolución constructiva que tuvo y cómo fue su desarrollo (Muñoz et al. 2014b: 759) (Figura 3). Constatamos que se trataba de un palacio construido en el Clásico Tardío, y que en un origen contaba con una sala principal (cuarto 3 ) desde la que se podía acceder a sendas cámaras laterales simétricas (cuartos 2 y 4). Es muy posible que estas salas sirvieran para almacenar objetos valiosos $u$ otra parafernalia que eran entregados como tributo o regalo al dirigente, y a las que sólo él y sus más allegados tenían acceso. Esta tipología se ha encontrado también en el Palacio de Oriente y en el Palacio 6J3 de la Acrópolis de La Blanca (Vidal et al. 2016: 285). En época más tardía el palacio adoptó forma de $\mathrm{U}$, al construirse en sus laterales dos alas simétricas y dando lugar a un gran patio central al que se accedería desde el sur mediante una escalinata (Figura 4). Cada una de esas alas posee una estancia principal con una gran puerta que abre hacia el patio central (cuartos 6 y 8), y otra interior, más pequeña, con una gran banqueta y con una sola puerta que comunica con la principal 
(cuartos 1 y 5). Sin lugar a dudas fue en ese momento cuando los muros de las salas principales se cubrieron de hermosas pinturas, de las que sólo se habían conservado las del cuarto 6 . Aun así, en el cuarto 3 se pudo identificar una fecha de cuenta corta en el inicio de una cenefa similar a la aparecida en el cuarto 6. Según Lacadena (2013), la fecha indicada más probable es dos años más tardía (772 d.C.) que la del cuarto 6 (770 d.C.), es decir, esas fechas podrían corresponder a la dedicación de la remodelación realizada en este excepcional conjunto palaciego.

\section{Conservación y documentación}

Tras el descubrimiento de las pinturas murales se comprobó que su estado de conservación era precario, debido a las diferentes vicisitudes por las que habían pasado. Recordemos que los mayas antiguos habían clausurado la sala y la habían rellenado con piedra y tierra y, aunque esta clausura contribuyó a su conservación, también fue la causa de que se generaran sustancias terrosas y barro adherido a la superficie, así como la aparición de sales en forma de capas blancas superficiales en ciertas zonas del cuarto. También se pudieron constatar materiales faltantes de la superficie pictórica y que algunas partes del estuco presentaban abolsamientos y separaciones del soporte de piedra caliza. Todo ello indicaba la necesidad de realizar una operación urgente de limpieza, saneamiento y consolidación de los murales para que pudiesen ser conservados adecuadamente y detener así los agentes de deterioro. Dichas tareas fueron llevadas a cabo en la temporada de campo 2011 por el equipo de restauración del Proyecto La Blanca, y supusieron un gran esfuerzo y dedicación debido al delicado estado de conservación de las pinturas (vid. Vidal et al. 2012).

También fue necesario considerar el deterioro del soporte pétreo de tipo calcáreo, con zonas donde se manifestaba un estado superficial altamente pulverulento originado por su erosión debido a diferentes factores. Esta situación de deterioro de la piedra caliza habría sido la causante de las lagunas que aparecen en los murales. Aunque había que diferenciar también la aparición de otras lagunas intencionadas, producidas posiblemente en el momento de la clausura, tales como el picado de los ojos de las figuras con un objeto punzante.

Este plan de urgencia de salvamento y consolidación se realizó en cuanto se vació la sala, aunque previamente aquellas zonas que presentaban fracturas o peligro de desprendimiento del estuco se habían protegido con papel tisú impregnado de resina acrílica en bajos porcentajes, para mantenerlas durante las operaciones de vaciado y tratarlas posteriormente. Una vez vaciada la sala se procedió a la fijación de las zonas de estuco con mayor peligro mediante la colocación de bordes perimetrales, compuestos con cal y arena del propio lugar, con la adición de resinas acrílicas en bajos porcentajes. También se realizaron inyecciones de resina en zonas puntuales e inyecciones de mortero en los abolsamientos de los estucos.

Las operaciones de limpieza se centraron primeramente en las áreas más deterioradas por la aparición de raíces que estaban tanto en el exterior como en el interior de los estucos y, en algunos casos, afectaban a los sillares pétreos. También se trataron las zonas con sales y las que presentaban sustancias terrosas, eliminándolas mediante una minuciosa acción mecánica con el empleo de escalpelo y bisturí, ya que no parecía adecuado otro tipo de desalaciones por la inestabilidad de las pinturas. 


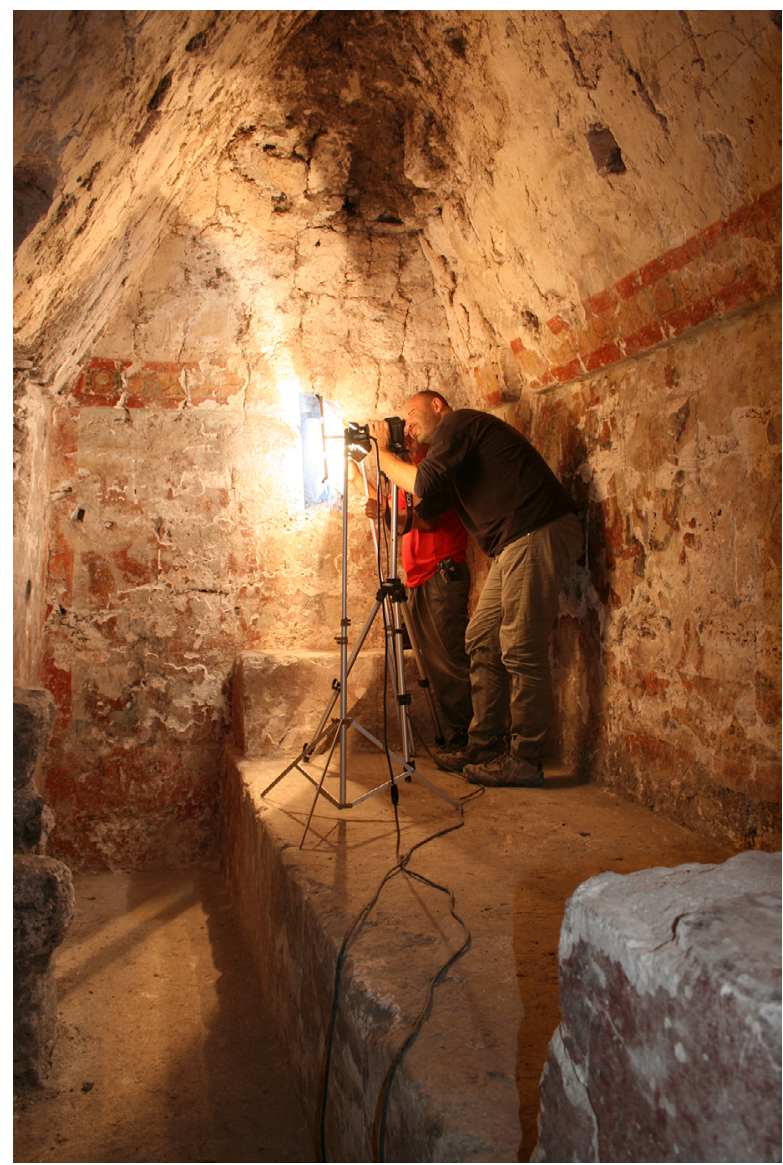

Figura 5. Levantamiento fotográfico en el interior del cuarto 6 (Fotografía de Patricia Horcajada).

Con todo ello se llegó a un estado suficientemente adecuado para iniciar el proceso de documentación, siempre necesario pero aún más urgente en este caso por su ubicación en un sitio desprotegido y con grave riesgo de destrucción. Para ello, inicialmente se realizó un levantamiento fotográfico de alta calidad por parte de un fotógrafo profesional (Figura 5). Esas fotos sirvieron para abordar los primeros estudios del estado y las características de los murales. Posteriormente, y una vez totalmente consolidados, se realizó un calcado de las pinturas para obtener una copia a tamaño real de los elementos más importantes del mural y poder generar una copia a escala de las pinturas visibles. Para colorearlas se utilizaron acuarelas y lápices de colores, procurando alcanzar la máxima aproximación a los colores originales.

También se procedió al calcado a tamaño natural de los glifos que aparecen en la cenefa superior y los intercalados entre las figuras del mural. De este trabajo se encargó Alfonso Lacadena, quien examinó directamente las pinturas, e incluso dibujó directamente alguno de los glifos, y pudo dirigir todas las operaciones de calcado de signos de escritura.

Por último, se llevaron a cabo otras dos operaciones para poder tener una información exhaustiva de la sala y de los murales. Por un lado, se procedió a escanear toda la sala con un escáner Faro Focus S 120 3D, generándose un sistema de nubes de puntos que sirvió tanto de apoyo para el levantamiento pormenorizado de la sala 
como para la creación de un modelo de tres dimensiones que reproduce con total fiabilidad la realidad volumétrica y formal de la sala de los murales. Por otro lado, para apoyar la textura del modelo, se procedió a una toma fotográfica minuciosa con el fin de generar modelos fotogramétricos de todos los elementos del cuarto.

En definitiva, la exhaustiva documentación llevada a cabo en esta sala ha permitido que hoy en día sea posible realizar una reproducción virtual de toda la cámara de forma absolutamente fiel a la realidad.

\section{Análisis formal}

Las pinturas del Palacio 3E1 fueron concebidas para ser observadas desde el interior del cuarto y sólo por parte de una audiencia reducida. Dado que en las estancias 3 y 8 no se han conservado, nos preguntamos si las escenas fueron esbozadas de forma independiente unas de otras o si formaban parte de un mismo programa pictórico. De ser así, también nos surge la pregunta de cuál sería la secuencia de lectura desde el patio central de este conjunto palaciego, es decir, cuál era el principio, cuál el nudo o conflicto, y cuál el desenlace o final de esta narración. Lamentablemente, esas preguntas nunca podrán tener respuesta, pero al menos sí nos queda la posibilidad de intentar desgranar la historia plasmada en el mural del cuarto 6 .

Otra pregunta que nos hacemos es la relativa a la iluminación, es decir, ¿con qué se iluminaban estas estancias? Esta misma pregunta se la hicieron también los investigadores de los murales de Bonampak, deduciendo que no se usaron antorchas dada la ausencia de restos de humo y hollín sobre las pinturas y proponiendo el uso de lienzos de color blanco (Miller y Brittenham 2013: 33), aunque ellos mismos admiten que esta práctica tiene sus limitaciones. En el caso de Chilonché creemos tener la respuesta ya que a diferencia de la Estructura 1 de Bonampak, cuyas puertas tienen una anchura inferior a $1 \mathrm{~m}$, en las de Chilonché se accedía desde el patio a través de vanos muy amplios, lo que garantizaba la entrada de luz exterior suficiente para iluminar las superficies pintadas.

En el caso del cuarto 6, la puerta mide 1,72 $\mathrm{m}$ de ancho y está situada en el centro del muro oriental, que es el que carece de escenas pintadas. La presencia en uno de sus laterales de un elaborado pasacordel cerámico de color azul es un testimonio de que de estas puertas podían cerrarse con algunos elementos, seguramente textiles, que eran asegurados en los pasacordeles, manteniendo de esta manera protegido el cuarto.

\subsection{Materiales y técnicas}

Los análisis arqueométricos de las muestras extraídas del mural del cuarto 6, realizados en el Laboratorio de análisis físico-químico y control medioambiental de obras de arte del Instituto de Restauración del Patrimonio de la Universidad Politécnica de Valencia (UPV) mediante el uso de numerosas y sofisticadas técnicas, han permitido definir los materiales, las técnicas de las bases de preparación y la paleta de color empleada por los pintores de Chilonché. En este sentido, uno de los resultados más reveladores surgió al combinar la técnica de cromatografía de gases/espectrometría de masas con la de pirolisis (Pyro-GC/MS), con la que se pudo comprobar en todos los pigmentos la ausencia de ligamento orgánico, lo que apuntaba, según el Informe 
del laboratorio, a que la técnica utilizada fue la del fresco, en la cual los colores son diluidos en agua y sin ayuda de otros aditivos se aplican sobre el sustrato calcáreo cuando todavía está húmedo. El proceso que se genera al evaporarse el agua provoca una carbonatación de la cal del enlucido, y con ello la formación superficial de una capa de carbonato de calcio que fija el color en su sustrato inferior (Vázquez de Ágredos et al. 2014: 173; Vidal et al. 2014: 152). Esto es algo totalmente inédito en el caso de la pintura mural maya; de hecho, los análisis realizados en los vestigios pictóricos del vecino sitio de La Blanca nunca arrojaron un resultado semejante, de ahí que sería deseable poder contar con más evidencias que apoyen esta hipótesis.

Por otro lado, el estudio por microscopio electrónico de transmisión (TEM) y microscopio de fuerza atómica (AFM) ha permitido determinar que los pigmentos a base de hierro empleados en Chilonché -un $88 \%$ de la paleta- fueron manipulados sometiéndolos a calentamiento, con el fin de conseguir diferentes tonalidades de rojos, amarillos, ocres y naranjas. Estos minerales (hematites, limonitas, ilmenitas y goethitas) sufrieron cambios en la matriz al someterse a temperaturas entre 600 y $800^{\circ} \mathrm{C}$, permitiendo tonalidades más oscuras frente a otras más luminosas en los casos en que los pigmentos no fueron sometidos a calor sino aplicados en su forma original, siendo este tipo de pigmento el que se aplicó en los personajes de la pared norte (Vázquez de Ágredos et al. 2014: 175). Otra innovación fue el hecho de que en esta pared el tamaño de las partículas de los pigmentos a base de hierro es mucho más fina, en comparación con las partículas de los pigmentos aplicados en las otras paredes, favoreciendo así la presencia de colores más saturados y menos luminosos.

Otros colores empleados fueron el negro carbón, el blanco de cal y los tradicionales azul y verde maya, obtenidos al mezclar el tinte del índigo con atapulgita y hornearlos a temperaturas no superiores a $\operatorname{los} 300^{\circ} \mathrm{C}$.

\subsection{Descripción general del mural del cuarto 6}

El mural se desarrolla a lo largo de los muros norte, oeste y sur. Durante los trabajos de documentación del interior de la cámara no se descubrieron en esos muros rastros de una posible trama o retícula concebida para situar las figuras que forman parte de las diferentes escenas, como sí se ha conservado, por ejemplo, en algunos murales del antiguo Egipto y también en Teotihuacan (De la Fuente 1996: 194) y del área maya (Miller y Brittenham 2013: 13). Lo que es muy posible es que en una fase preparatoria los pintores de Chilonché hayan marcado, al menos, los principales trazados reguladores que delimitan el espacio compositivo del mural, aunque no se ha encontrado ninguna huella visible. También existe la posibilidad de que hayan existido bocetos con todo el programa pictórico hechos en corteza de árbol u otro soporte por nosotros desconocido, asegurándose así una correcta representación de las escenas cuando éstas fueron trasladadas a cada uno de los muros.

La bóveda no está pintada -salvo la cenefa que recorre su parte inferior-, como sí ocurre en Bonampak, donde al ingresar en cada una de las cámaras el espectador se encuentra totalmente envuelto por el espacio pictórico ya que todos los muros están pintados. En el caso de Chilonché, al existir paredes y espacios sin pintar es posible lograr una mayor concentración a la hora de contemplar las pinturas.

Las paredes norte y oeste albergan una única escena mientras que en la pared meridional se distinguen dos que están separadas por una franja horizontal. Estas dos escenas tienen diferente tamaño, ya que la inferior se detiene al topar con el 
brazo sur de la banqueta y, además, su altura es inferior. La cenefa con inscripciones jeroglíficas que recorre el arranque de la bóveda enmarca todo el mural por la parte superior; está formada por dos anchas franjas horizontales de color rojo que actúan como marco del espacio de color amarillo en el que se delinearon los signos escriturarios, separados a su vez por bandas verticales de color verde-azul. Por otro lado, los laterales del mural están delimitados en cada pared por anchas franjas verticales de color rojo, adaptándose la del extremo oriental de la pared norte a la forma del vano que da acceso al cuarto 5. Una franja horizontal, algo más delgada y del mismo color, delimita también el extremo inferior de las paredes sur y norte, mientras que la gran escena de la pared oeste descansa sobre una franja de color amarillo de unos $26 \mathrm{~cm}$ de alto, decorada con un diseño de piel de jaguar. Debajo de ésta, la pared está pintada de rojo hasta morir en el borde longitudinal de la banqueta.

Se trata, por tanto, de un espacio pictórico que fue concebido de forma similar al de las vasijas polícromas, en las que predominan las cenefas jeroglíficas en la parte superior, y franjas rojas y negras enmarcando las escenas. La cenefa con diseño de piel de jaguar constituye una excepción y resulta muy original, si bien existen algunos ejemplos similares en vasijas, como es el caso de la K6041.

En las escenas, se han podido documentar más de ochenta figuras humanas, un ave y diversos objetos. En las figuras humanas, la ratio cabeza-cuerpo oscila entre 1:5 y 1:6, una media también habitual en las figuraciones de Bonampak, donde la anchura de las figuras -sin adornos y atuendo- es de 1/4 de la altura (Miller y Brittenham 2013: 15), al igual que en Chilonché.

Los rostros de todos los personajes están de perfil, destacando en ellos los grandes ojos almendrados delineados en negro, aunque la mayor parte de ellos han sido picados de forma intencional, presumiblemente cuando se clausuró el cuarto. Los cuerpos, por el contrario, aparecen de diferentes maneras: de frente, de perfil o en posición de 3/4. La presencia de figuras superpuestas y algunas en escorzo constituye un hábil recurso empleado por el pintor de Chilonché para generar sensación de profundidad. Quizás, donde mejor se aprecia el escorzo es en la figura sedente en el registro inferior de la pared sur.

La forma de representar las manos, los pies, los ojos y el resto de las características que definen a los personajes parece indicar que las figuras fueron trazadas por un único artista, alternando las delineadas en negro con las que presentan un contorno de color rojo.

\subsection{Singularidades formales y cualidades expresivas}

PARED SUR: Como decíamos, en esta pared hay dos escenas (Figura 6). La inferior, delimitada por un marco de franjas rojas, está compuesta por cuatro individuos, uno de ellos sentado, y los otros tres de pie cuyas cabezas y tocados sobresalen por encima de la franja superior. El personaje sedente tiene la piel de color rojo, dirige su mirada hacia el oeste, su torso está de frente y sus piernas están flexionadas a la manera oriental en un marcado escorzo, siendo éste un convencionalismo habitual en las representaciones de los dirigentes mayas $\mathrm{y}$, a veces también, de los escribas y las divinidades (véase, a modo de ejemplo, las vasijas K2784, K4585, K1185, K8425 o K5184). Los brazos de este personaje están en actitud de recibir una prenda de color azul que le entrega el personaje que está de pie con la piel pintada de color negro y que inclina su torso para dirigirse hacia él, entablando ambos una comunica- 


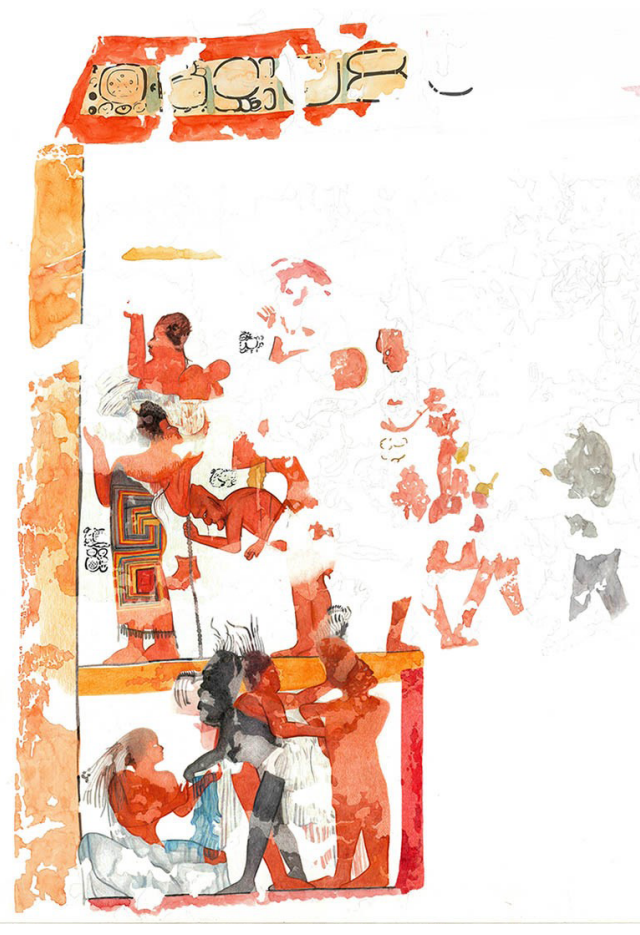

Figura 6. Reproducción del mural de la pared sur (Dibujo de Miguel Ángel

Núñez. (C) PLB 2018).

ción visual. Éste está situado delante de otro individuo con la piel de color rojo pero cuyo cuerpo se dirige hacia el lado opuesto. Las piernas de ambos están entrelazadas dando lugar a un hermoso juego de superposición de planos que confiere un fuerte contraste y gran dinamismo a la escena. Finalmente, el cuarto individuo, con la piel también pintada de rojo, mantiene una forzada postura al tener el rostro totalmente girado hacia el oeste, los hombros de frente, pero las caderas y las piernas de perfil, en dirección opuesta a la del rostro. Otra singularidad es que su mirada parece dirigirse a la escena situada en el nivel superior, invitando al espectador a dirigir su mirada hacia arriba.

La escena superior está integrada por dos niveles, uno encima del otro, permaneciendo el superior en gran parte oculto por el inferior. En este último destaca la presencia de dos figuras femeninas que han podido ser identificadas gracias a la existencia de signos escriturarios junto a ellas. Nos referimos al personaje que viste un elegante vestido -huipil-, con diseño de greca de diversos colores, y a la anciana apoyada en un bastón que se inclina detrás de ésta. La dama del huipil mantiene una postura igual de forzada que el personaje del registro inferior: rostro de perfil mirando hacia el oeste, hombros de frente y cadera y piernas de perfil en la dirección contraria, con los brazos flexionados y levantados hacia arriba. Además del original diseño de su huipil, éste destaca también por la transparencia de la parte inferior, algo que no es desconocido en los huipiles de las mujeres mayas del periodo Clásico, como es el caso de la mujer del huipil azul de los murales de Calakmul o el bellísimo vestido que luce la Señora de Tikal en la vasija K2573. En el caso de la anciana, llama la atención su escaso atuendo y el perfil contorneado de su bastón, resultando muy conmovedora la excesiva inclinación de su cuerpo. Otros personajes están situados en este mismo nivel, si bien el mal estado de conservación del muro en este sector impide saber cuántos son. En el nivel superior hay otra figura representada de perfil y con el brazo izquierdo levantado, justamente encima de la mujer con huipil, pero mirando hacia el lado contrario que ésta. Su rostro presenta cierto prognatismo y en su espalda sobresale un llamativo bulto del mismo color de su piel que podría estar indicando una joroba u otra malformación, como la que muestra, por ejemplo, uno de los personajes de la vasija K9113.

PARED OESTE: Esta pared es la que exhibe el mayor número de personajes (Figura 7), destacando sobre todo los de la mitad meridional debido a su buen estado de conservación. La parte peor conservada es la central y la de los extremos norte y sur, 


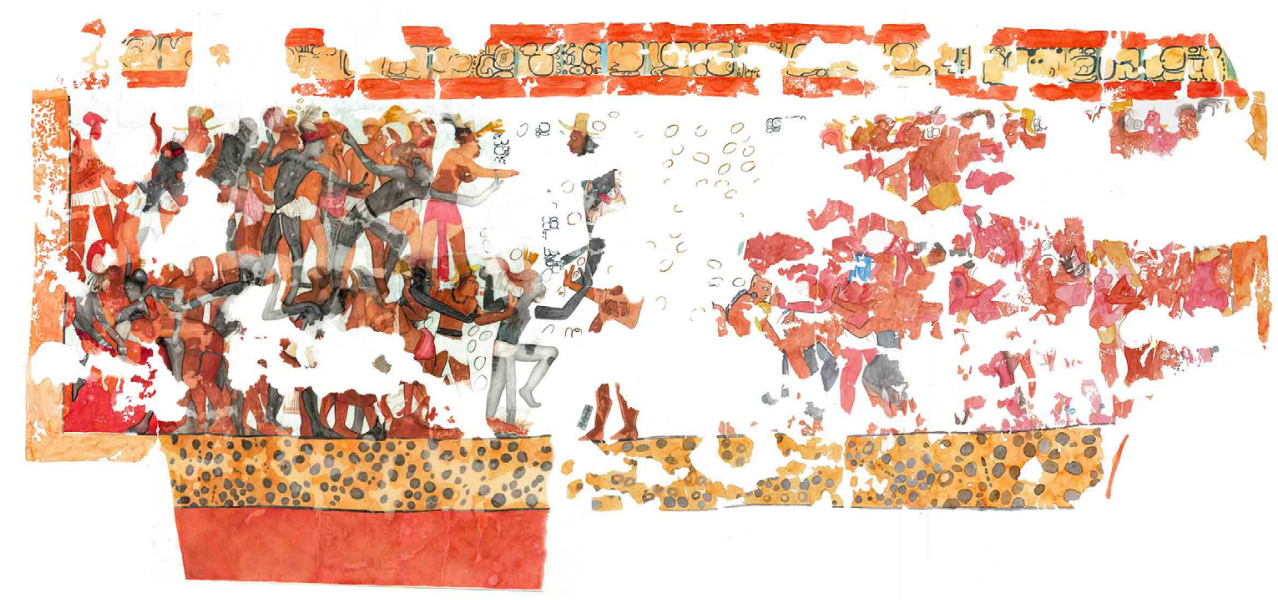

Figura 7. Reproducción del mural de la pared oeste.

(Dibujo de Miguel Ángel Núñez (C PLB 2018).

pero aun así se han podido contabilizar más de sesenta figuras humanas concentradas en los $6,56 \mathrm{~m}^{2}$ sobre los que se extiende el mural.

Otra singularidad de esta composición es un primer intento del pintor de establecer una profundidad de campo en la pintura, tratando de dar espacialidad a las mismas mediante lo que podría entenderse como un sistema rudimentario de perspectiva. Para ello sitúa a los personajes en dos niveles superpuestos que alcanzan una altura total de $110 \mathrm{~cm}$. El nivel inferior mide $62 \mathrm{~cm}$ de alto, al igual que el superior, pero éste tiene aproximadamente una cuarta parte oculta por los personajes del nivel de abajo, de ahí que sólo lo supera en $48 \mathrm{~cm}$. Los personajes están distribuidos de forma equilibrada, no todos tienen la misma altura, y aunque están representados en diferentes posturas y unos delante de otros, es decir, en diferentes planos, cada uno se mantiene en el nivel al que pertenece. Estos niveles superpuestos constituyen un innovador recurso, en el que el nivel inferior podría entenderse como la parte más próxima de la escena, al tiempo que se crea en el espectador una sensación de lejanía en el espacio del nivel superior. Un recurso similar se aprecia también en las escenas de la batalla de los muros este, sur y oeste de Bonampak. En este caso es interesante hacer notar que los murales de Bonampak hacen alusión a sucesos ocurridos en el 790 d.C., es decir, una fecha más tardía que la que exhiben los textos de Chilonché (770 d.C.)

Los individuos son todos aparentemente masculinos, sus cuerpos están pintados de color rojo, ocre o negro, están semidesnudos, apenas ataviados con un ligero taparrabos y dos de ellos lucen un collar de cuentas. Algunos portan tocados mientras que otros exhiben sombreros de copa alta, ala ancha y color amarillo, sobre todo los que se encuentran en la mitad norte de la composición. Como decíamos, están dispuestos unos delante de otros, la mayoría de ellos con los brazos estirados y en diferentes posturas, lo que dota al mural de gran dinamismo. Si nos detenemos en el conjunto de individuos concentrados en la mitad sur de esta pared observamos cómo en el nivel superior, dos de ellos, pintados de negro, con sus torsos inclinados y los brazos muy estirados, están colocados delante del grupo de personajes pintados de 
color ocre que mantienen posturas más erguidas, creando un fuerte efecto dramático en el espectador. Esa misma tensión se aprecia en el nivel inferior, en el que aparece un individuo totalmente doblado que es sujetado por otros, un personaje que sostiene un objeto contundente de gran tamaño, aparentemente una piedra, a punto de golpear con ella a otro que se encuentra más abajo, otro que yace horizontalmente a los pies del mural, y el situado en el extremo norte de este conjunto, con la piel pintada de negro y levantando la pierna izquierda en actitud de lanzarse hacia el personaje de color ocre que tiene enfrente. Los brazos de ambos se superponen, marcando en ese lugar de la composición el encuentro entre los individuos de la mitad sur que miran hacia el norte, y los de la mitad norte que, en su mayoría, dirigen sus miradas hacia los de la otra mitad. Es muy posible que el personaje con la pierna levantada sujete también en su mano derecha una piedra, aunque el estado de conservación del mural en esta parte no permite afirmarlo con rotundidad.

Es interesante resaltar que la parte central de la pared es la más despejada en cuanto a figuraciones, apreciándose en ella una gran cantidad de objetos ovales, que podrían estar representando piedras.

A continuación de ese espacio se concentra el grueso de figuras que conforman la mitad norte de la composición. Aunque la mayor parte de los individuos mira hacia el sur, algunos lo hacen en sentido contrario, como es el caso del personaje que porta un collar de cuentas que le cuelga por la espalda y que con sus brazos levantados parece contener al resto de individuos que se abalanzan hacia él. Tanto este hecho como el que las figuras aparezcan muy incompletas debido al mal estado de conservación de este sector, parece ser la causa de que esta parte del mural cause una mayor confusión en el espectador. Debido a ello tampoco se puede reconocer a qué corresponde el fragmento de color azul que aparece en medio de todos estos individuos, pero que por su coloración atrae la mirada del observador.

Al igual que ocurre en las otras paredes, pequeños paquetes jeroglíficos fueron dibujados junto a algunos de los personajes de esta escena.

PARED NORTE: De lo que se ha conservado de la pared norte se deduce que también existieron dos niveles de representación (Figura 8), estando el superior parcialmente oculto por el inferior. En total se distinguen nueve personajes humanos con la piel de color rojo, de los cuales todos, excepto uno, están mirando hacia el este. El único que mira en dirección contraria es el individuo del nivel inferior que se apoya en el extremo oriental de esta pared, cerrando de esta manera la escena. Este personaje presenta unos rasgos faciales con prognatismo y lo que parece ser una joroba en la espalda; dado su tamaño podría decirse que está sentado, aunque también podría tratarse de un niño o de un enano. Junto a él hay un individuo que sostiene en sus brazos una hermosa guacamaya de color azul y un cuenco en su mano izquierda. Otro de los objetos que destaca en esta escena es el que porta uno de los personajes del nivel superior que, a manera de procesión, se dirigen hacia el final de esta pared. Se trata de una pieza de forma rectangular, decoración geométrica $\mathrm{y}$, al menos, una pata de tipo losa, sorpresivamente similar al objeto que porta el individuo representado en la vasija K2345 (Figura 9).

Desde el punto de vista de la composición puede decirse que las escenas representadas en estas tres paredes del cuarto 6 destacan por su asimetría, la cual se reitera por una serie de oposiciones: la presencia de niveles superpuestos en cada una de las escenas, implicando espacialidad y lejanía, y de personajes situados en diferentes planos, creando un efecto de tridimensionalidad y huyendo en todo momento de la 


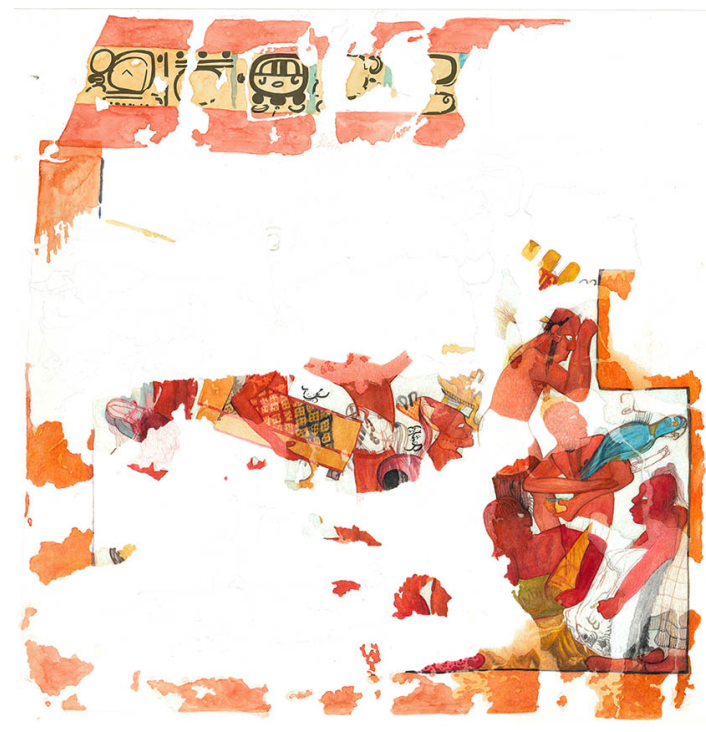

Figura 8. Reproducción del mural de la pared norte. (Dibujo de Miguel Ángel Núñez (C) PLB 2018).

Figura 9. Escena representada en la vasija K2345. (Imagen (C) Justin Kerr, Kerr Database).

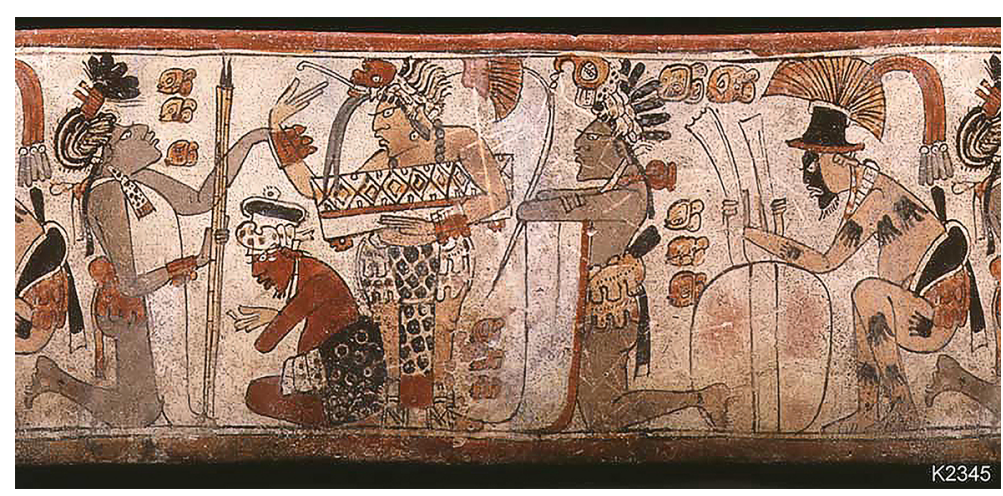

ley de la frontalidad. Otro aspecto a destacar es que la práctica totalidad de los hombres con la piel pintada de negro se concentra en la escena de la mitad sur de la pared oeste, dotando a este sector de un fuerte contraste cromático al recortarse sus cuerpos sobre la superficie roja de la piel de los demás personajes. Otros colores llamativos son los del diseño de greca en el huipil de la dama del lado sur, así como el color azul del lienzo que recibe el personaje sentado en el extremo inferior de esa misma pared, el fragmento que se vislumbra en el centro de la composición de la pared oeste, y el de la guacamaya que está encima del personaje sentado en el extremo inferior de la pared norte.

En definitiva, los pintores de Chilonché eran profundos conocedores de los convencionalismos que caracterizan al arte pictórico maya, al tiempo que supieron idear una serie de recursos ópticos destinados a provocar situaciones de gran dinamismo, tensión y dramatismo. Su contemplación debió suscitar profundas emociones en los espectadores que tuvieron la dicha de conocer todo el programa pictórico diseñado para este palacio, cuya calidad es equiparable a la de las célebres pinturas de Bonampak, realizadas dos décadas más tarde. 


\section{Aproximación al significado}

Como decíamos, la presencia de menciones escriturarias en las tres paredes nos ha permitido conocer los nombres o títulos de algunos de los personajes, de cuya traducción se encargó Alfonso Lacadena, quien escribía lo siguiente en su Informe preliminar sobre la investigación epigráfica: «Un total de catorce textos jeroglíficos menores aparecen insertados entre las figuras de las escenas representadas en el mural del cuarto 6, tres en la pared sur, nueve en la oeste y dos en la norte, la mayoría de ellos asociados a los personajes. Dada la pérdida de la superficie pictórica en ciertos lugares del mural, no hay que descartar que otros personajes hubieran tenido originalmente también cláusulas glíficas asociadas. Estos textos jeroglíficos son muy breves, entre uno (la mayoría) y cuatro bloques jeroglíficos. Por el patrón habitual que se encuentra en otras representaciones mayas y el contenido de los textos, podemos determinar que la mayoría de los ejemplos representan los nombres o títulos de los personajes con los que se relacionan» y que «todos los personajes del mural mencionados tienen nombres o títulos históricos, típicos del periodo Clásico maya y que por tanto las escenas del mural son históricas, y no mitológicas» (Lacadena 2013).

Entre los mejor conservados se encuentran los que acompañan a los personajes femeninos de la pared sur: la dama del huipil, Ix K'anpat Ajaw, princesa de K'anpat y la anciana, Ix Sutz o Señora Murciélago, según la traducción de Lacadena (Muñoz y Vidal 2018: 59). Es interesante hacer notar que el topónimo K'anpat vuelve a aparecer junto a uno de los personajes de la pared oeste, lo que parece indicar que lo que se representa en este mural son sucesos relevantes de la historia local, en los que personajes vinculados al sitio de K'anpat, que quizás sea el propio Chilonché u otro del entorno, juegan un papel destacado.

Más adelante, Lacadena estuvo trabajando en la traducción de la cenefa jeroglífica que recorre todo el mural, llegando a conclusiones muy sugerentes que aún faltaba corroborar con la iconografía. Lamentablemente este estudio no se pudo culminar debido a su fallecimiento, de modo que esperamos poder presentarlo próximamente, como complemento a esta aportación.

Debido a ello, en este apartado ofreceremos sólo algunas pinceladas acerca del contenido de este mural, fijándonos exclusivamente en la representación iconográfica. En este sentido, y al hilo de lo expuesto anteriormente, no parece descabellado pensar que lo que se representa en la escena principal, la de la pared oeste, es un enfrentamiento entre los individuos de la mitad norte y los de la mitad sur de este muro, siendo el arma arrojadiza las piedras. Éstas aparecen de forma muy explícita en el centro de la composición y presumiblemente también en las manos de los hombres pintados de negro de la mitad sur, que por las posturas que exhiben parecen estar representados en el momento de lanzarlas. Es decir, coincidiendo con el eje central del cuarto y también de la banqueta, lo que se muestra es el fragor de la batalla. Esta escena es muy original, ya que aunque en otros murales mayas como los de Bonampak o Mulchic (vid. Mayer 1990: 38-39) aparece el uso de piedras como arma arrojadiza, en ambos casos éstas son lanzadas por individuos que se encuentran mezclados con muchos otros guerreros ataviados con sofisticados atuendos y blandiendo armas más elaboradas (lanzas y cuchillos), sin embargo, en el caso de Chilonché, las únicas armas que se aprecian son las piedras. En su utilización distinguimos dos tipos de acciones: la de lanzarlas a distancia, siendo muy similar la postura de los hombres de color negro de la mitad sur con la de los que aparecen en esa misma actitud en el 
muro poniente del cuarto 2 de Bonampak, y la acción de apedrear a algún individuo concreto más cercano. En este último tipo de ataque se utiliza una piedra más grande, siendo así cómo lo hace el individuo de color ocre y taparrabos rojo en el nivel inferior de este sector del mural de Chilonché y el individuo del mural 1 de Mulchic, o los personajes de algunas vasijas polícromas (K7516, K9149).

En contraste con estas acciones violentas, los individuos de la mitad norte parecen querer contener el ataque, o al menos la postura de los brazos de algunos de ellos así lo indica. Es probable que éstos sean los de K'anpat, ya que este topónimo es el que aparece junto a uno de ellos. Dos de sus representantes, uno de los cuales porta un sombrero amarillo de ala ancha, son los que establecen contacto visual e incluso físico con los violentos de la mitad sur, buscando, quizás, el diálogo y la resolución del conflicto.

Por último, entre los del tumulto de la mitad norte destaca especialmente el personaje que porta un collar y que está en el centro mirando hacia ellos, y a quien Lacadena quiso relacionar con los personajes con joroba de los muros sur y norte, respectivamente, una hipótesis que aún está por verificar.

Las representaciones de los muros norte y sur transmiten mucha menos tensión, y como ya hemos visto, en el caso de la pared sur, se menciona a una mujer del linaje real de K'anpat que sin duda se muestra alarmada por los acontecimientos de la pared oeste, hacia los cuales dirige su mirada. Dos de los personajes del registro inferior también parecen alertados por esa situación, de ahí la forzada postura de uno de ellos girándose hacia ese lado, a diferencia de los dos personajes de la izquierda que parecen concentrados en el intercambio de la prenda azul. Recordemos también que en este muro se muestra un personaje con joroba y rasgos faciales singulares, al igual que el que cierra toda la composición en el muro norte.

La escena de la pared norte podría interpretarse como la habitual procesión de individuos que cargan lujosos objetos, a modo de presentes o tributo, destacando entre éstos el objeto con forma de caja, decorada con motivos geométricos. Un objeto similar es el que aparece, como ya se ha dicho, en la vasija K2345, pero también es revelador que otros muy parecidos, interpretados como cajas o banquetas, hayan sido plasmados en los murales de Dzula (vid. Mayer 1990: 31) y Bonampak (muro poniente del cuarto 2, encima de los personajes que lanzan piedras). En este último ejemplo, ese mismo objeto vuelve a aparecer en el cuarto 3, debajo del trono de las mujeres que realizan un auto-sacrificio. En nuestro caso nos inclinamos por considerarlo una caja o cofre, el cual podría contener objetos valiosos obtenidos tras la refriega, coincidiendo con lo que piensan Miller y Brittenham (2013: 100) para el caso de Bonampak.

Es muy posible que la guacamaya azul también forme parte de esos hermosos tributos y que el individuo con joroba - ¿un enano?- que cierra la escena sea un miembro de la corte encargado de comprobar la calidad de los tributos que le serán entregados a su señor o señora, o al menos así es como se ha interpretado en iconografía maya la presencia de personas con malformaciones como el enanismo y la gibosidad, siendo un ejemplo muy ilustrativo de ello las escenas representadas en las vasijas K1453, K8774 y K1563. Según Prager, el hecho de que estos individuos desempeñen un papel tan importante como acompañantes y servidores de los gobernantes se debe a que dichas malformaciones humanas simbolizan una especie de nexo de unión entre el mundo real y el irreal «pues ellos reciben, debido a su singularidad física, un atributo divino que los diferencia claramente de otros seres 
humanos, y posiblemente han sido escogidos por los seres sobrenaturales para portar sus tributos» (Prager 2002: 53).

En definitiva, en esta fase preliminar del análisis iconográfico, y sin poner aún en relación la imagen con el texto de la cenefa jeroglífica, podemos concluir diciendo que este mural nos relata una historia que comienza en la pared sur, cuando la Señora de K'anpat y demás personajes son alertados de los sucesos plasmados en la pared oeste. Estos acontecimientos, que constituyen el nudo del relato, conllevan un enfrentamiento protagonizado por individuos que no van ataviados como guerreros ni portan sofisticadas armas, sino que tan solo están armados con piedras. Es posible que se trate de un ataque a la población de K'anpat y que finalmente el conflicto haya sido resuelto por los mediadores de esta localidad. Finalmente, el desenlace sería la entrega de tributos. Pero ¿a quién iban destinados esos tributos? Barajamos dos posibilidades: una podría ser que el destinatario sea el Señor o la Señora de K'anpat, y que el relato continúe en el cuarto central del Palacio 3E1 (cuarto 3), y la otra, que el receptor de los regalos sea el personaje con joroba, desechando así la idea anteriormente expuesta acerca de la función que este tipo de personaje desempeñaba en las cortes mayas. Éstas serán las hipótesis con las que partiremos en la siguiente fase de investigación de este mural, sustentándonos para ello en la traducción del texto jeroglífico, ya iniciada por Lacadena.

\section{Un patrimonio en riesgo}

El detallado estudio de este mural nos ha permitido constatar que nos hallamos ante un patrimonio cultural de carácter único, revelador de que pintores mayas de la talla de los de Bonampak ya estaban realizando obras de similar relevancia, al menos dos décadas antes. Por otro lado, dado que son contados los murales que se conservan en el área maya en unas condiciones similares, susceptibles de ser apreciados en todas sus dimensiones culturales y de generar abundante información sobre su contenido y sobre la cultura maya del Clásico Tardío, su descubrimiento supuso un hallazgo de indudable interés científico. Pero lamentablemente las condiciones de trabajo en el Valle del Mopán no son muy favorables para proteger y conservar estos bienes culturales. Ello se debe en gran medida a que las propiedades de los sitios arqueológicos están en manos de particulares, que las recibieron hace algunas décadas como lotes de terreno por parte del Gobierno de Guatemala para su aprovechamiento agrario y ganadero. Debido a que la presencia de vestigios arqueológicos en algunos de esos terrenos imposibilita el llevar a cabo dichas actividades, una forma de sacar provecho de estas tierras se produce, en muchos casos, mediante el saqueo de los montículos.

Por ello, ante un descubrimiento como el de los murales de Chilonché realizado en el año 2011 hubiese sido necesario adoptar de inmediato las medidas previstas de expropiación, de delimitación del terreno y de vigilancia y protección para evitar el posible daño o destrucción de tan importantes muestras del arte mural maya. Pero no fue así y, a pesar de los informes presentados en todas las temporadas de campo a las autoridades guatemaltecas sobre los trabajos realizados y sobre las características singulares de estos murales, nunca se adoptaron por parte de la administración las medidas oficiales de protección, destinadas a evitar cualquier agresión a los mismos. Lamentablemente, y a pesar de todos los esfuerzos realizados por dejar siempre la sala sellada con un muro de mampostería, en el año 2017 fuimos informados de que 
se había producido un nuevo saqueo que penetró en la sala de las pinturas, provocando la destrucción de casi la totalidad del mural.

Afortunadamente, el riguroso proceso de documentación llevado a cabo en el interior de esta sala ha permitido su salvaguarda con fines científicos y de difusión a la sociedad, pero a efectos patrimoniales se trata de una pérdida irreparable.

Agradecimientos: Los autores agradecen expresamente el patrocinio del Ministerio de Educación, Cultura y Deporte de España a través de la financiación obtenida por el Proyecto La Blanca y su entorno, dentro del programa de ayudas para Proyectos Arqueológicos en el Exterior, así como del Ministerio de Economía y Competitividad, a través de la financiación de los proyectos de investigación coordinados con número de referencia BIA2011-28311-C02 y BIA2014-53887-C2 sobre Arquitectura maya, sistemas constructivos, estética formal y nuevas tecnologías, de la Fundación Príncipe Claus de Holanda, de la Fundación Palarq y el apoyo del Ministerio de Cultura y Deportes de Guatemala, que han contribuido de forma determinante a hacer posible esta investigación.

\section{Referencias}

Chocón, Jorge E., Heidy I. Quezada y Héctor E. Mejía. 1999. «Acrópolis de El Chilonche, Petén: Resultados de los sondeos y excavaciones», en XII Simposio de Investigaciones Arqueológicas en Guatemala 1998, Juan Pedro Laporte y Héctor L. Escobedo, eds., pp. 273-295. Guatemala: Museo Nacional de Arqueología y Etnología.

De La Fuente, Beatriz, coord. 1996. La pintura mural prehispánica en México. I Teotihuacán. Tomo II Estudios. México: Instituto de Investigaciones Estéticas, Universidad Nacional Autónoma de México.

Lacadena García-Gallo, Alfonso. 2013. «Investigación epigráfica preliminar», en Informe final de las actividades del proyecto Los murales mayas del sitio arqueológico de Chilonché, Cristina Vidal Lorenzo y Gaspar Muñoz Cosme, eds., Documento 2. Informe inédito entregado al Prince Claus Fund. Valencia: Universitat de València.

Mayer, Karl H. 1990. «Maya-Wandmalereien in der Puuc-region (Mexiko)». Antike Welt. Zeitschrift für Archäologie und Kulturgeschichte 21: 26-44.

Miller, Mary y Claudia Brittenham. 2013. The Spectacle of the Late Maya Court. Reflections on the Murals of Bonampak. Austin: University of Texas Press.

Muñoz Cosme, Gaspar y Cristina Vidal Lorenzo. 2018. «De Oxkintok a K'anpat», en Tiempo detenido, un tiempo suficiente: ensayos y narraciones mesoamericanistas en homenaje a Alfonso Lacadena García-Gallo, Harri Kettunen, Verónica A. Vázquez, Felix Kupprat, Cristina Vidal Lorenzo, Gaspar Muñoz Cosme y Ma Josefa Iglesias Ponce de León, eds., pp. 47-62. Couvin: Wayeb Publication Series, vol. 1.

Muñoz Cosme, Gaspar, Cristina Vidal Lorenzo y Alessandro Merlo. 2014a. «La Acrópolis de Chilonché (Guatemala) Crónica de las investigaciones de un patrimonio en riesgo en el área maya». Restauro Archeologico 22 (2): 98-115.

Muñoz Cosme, Gaspar, Cristina Vidal Lorenzo, Patricia Horcajada Campos, Óscar Quintana Samayoa, Zacarías Herguido Alamar y Miriam Salas Pol. 2014b. «Del Preclásico al Postclásico, la historia constructiva de un sitio del sureste de Petén: Chilonché», en XXVII Simposio de Investigaciones Arqueológicas en Guatemala 2013, Bárbara Arroyo, Luis Méndez y Andrea Rojas, eds., pp. 757-767. Guatemala: Museo Nacional de Arqueología y Etnología. 
Prager, Christian. 2002. «Enanismo y gibosidad. Las personas afectadas y su identidad en la sociedad maya del tiempo prehispánico», en La organización social entre los mayas prehispánicos, coloniales y modernos. Memoria de la Tercera Mesa Redonda de Palenque, Vera Tiesler, Rafael Cobos y Merle Greene Robertson, eds., Vol. II, pp. 35-67. México: Instituto Nacional de Antropología e Historia, Universidad Autónoma de Yucatán.

Vázquez de Ágredos Pascual, Ma Luisa, Cristina Vidal Lorenzo y Gaspar Muñoz Cosme. 2014. «The Role of New Technology in the Sudy of Maya Mural Painting: Over a Century of Progress», en Artistic Expressions in Maya Architecture: Analysis and Documentation Techniques, Cristina Vidal y Gaspar Muñoz, eds., pp. 165-178. BAR International Series 2693. Oxford: Archaeopress.

Vidal Lorenzo, Cristina, Gaspar Muñoz Cosme y Ma Luisa Vázquez de Ágredos Pascual. 2014. «Reflexiones en torno al arte y la conservación del patrimonio cultural maya: El Proyecto La Blanca, un proyecto piloto de investigación y cooperación internacional», en La piel de los edificios, Daniel Benito Goerlich, ed., pp. 141-158. Valencia: Universitat de València.

Vidal Lorenzo, Cristina, Gaspar Muñoz Cosme y Begoña Carrascosa Moliner. 2012. «El Cuarto de las pinturas de Chilonché», en Informe de las investigaciones arqueológicas del Proyecto La Blanca-Chilonché, Petén, Guatemala (Noviembre 2011-Enero 2012), Cristina Vidal y Gaspar Muñoz, eds., pp. 150-163. Informe inédito entregado al Ministerio de Cultura e Instituto de Antropología e Historia de Guatemala. Valencia: Universitat de València.

Vidal Lorenzo, Cristina, Ma Luisa Vázquez de Ágredos Pascual y Gaspar Muñoz Cosme. 2016. «Storage Places in the Maya Area», en Storage in Ancient Complex Societies, Linda R. Manzanilla y Mitchell S. Rothman, eds., pp. 271-292. Nueva York: Routledge. 